\title{
Unexpected Oscillations in Fire Modelling Inside a Long Tunnel
}

\author{
Chin Ding Ang*, Guillermo Rein and Joaquim Peiro, Imperial College London, \\ South Kensington, London SW7 1AL, UK
}

To the editor

We want to highlight the importance of establishing a best practice guideline for the computational modelling of large fires in tunnels. Tunnels are expensive critical infrastructure designed for 100 years or more, and computational tunnel fire modelling forms a critical tool in their design. However, there is still a lack of knowledge sharing in tunnel fire modelling across the industry. Tunnels is part of a sector with an unprecedented investment of over $\$ 700$ billion dollars in 2017 [1] and the investment has continued.

When modelling fires using Fire Dynamics Simulator [2] in long tunnels, we observed that mass flow oscillates with a non-negligible amplitude of $20 \%$ or more. Using this oscillatory behaviour, we want to highlight our belief that there is still a lack of knowledge sharing in tunnel fire modelling, and two suggestions on improving the status quo.

We were investigating the capabilities of FDS6.1.1, 6.5.3 and 6.6.0 for multiscale fire simulations with the $1.5 \mathrm{~km}$ Dartford Tunnel London, UK as a basis [3]. The tunnel has an area of $40.96 \mathrm{~m}^{2}$ with 7 pairs of jet fans at both ends, totalling 14 pairs. Each fan is at $8.9 \mathrm{~m}^{3} / \mathrm{s}$. We considered various fire sizes between $30 \mathrm{MW}$ and $75 \mathrm{MW}$. We noted an unexpected large oscillatory behaviour for the mass flow when interrogating the modelling results as shown in Figure 1. Similar oscillatory behaviour in both velocity and temperature predictions measurements is reported by Vermesi et al. [4].

When we first noted the oscillation, we decided to investigate further as Gresho et al. [5] said, "don't suppress the wiggles". Oscillation in tunnels during a fire has not been reported in scientific literature or engineering reports as far as we know after an extensive search. We were unable to find any source discussing the presence of oscillation in tunnel including the FDS forum or other specialists.

We established the oscillation only occurs when a fire over $30 \mathrm{MW}$ is introduced in this tunnel. We modified the fire growth by introducing a slower $t^{2}$ curve to minimise abrupt changes that could trigger numerical artefacts. We continue observing oscillations but with a smaller fluctuation of 5 to $10 \mathrm{~kg} / \mathrm{s}$.

Our model has a single mesh with extended domain beyond the portals and this eliminates multiple meshes as a cause of numerical artefacts.

\footnotetext{
*Correspondence should be addressed to: Guillermo Rein, E-mail: g.rein@imperial.ac.uk
} 


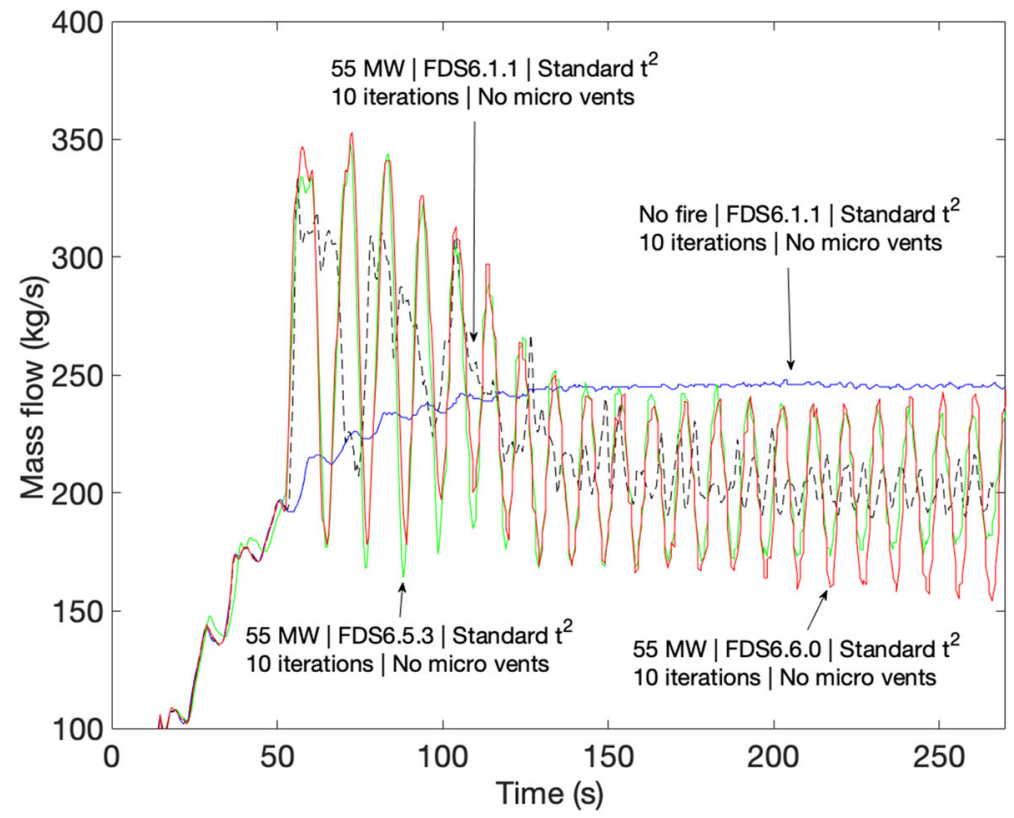

\section{Figure 1. Comparison of predicted mass flow out of the tunnel for no fire and 55 MW fire in three FDS versions. Oscillations can be seen for all three fire simulations but not in the no fire model.}

The FDS Guide [2] notes an option for the pressure solver to tighten the error tolerances by increasing the maximum iterations (default is 10 for FDS6.6.0). In Figure 2, we see that by increasing the iterations of the pressure solver to 30 , the oscillation appears at $50 \mathrm{~s}$ grows by $75 \%$ and then gradually reduces. Although more iterations were specified, the pressure solver only computed up to 14 iterations indicating the tolerances have been fully met.

Although the oscillation in the mass flow reduces with increasing iterations, the velocity error continues to be large at over $10 \mathrm{~m} / \mathrm{s}$. This indicates there is an underlying numerical issue with the pressure solver. We have not attempted to tighten the error tolerance related to the grid size due to the impractical increase in computational resources needed in terms of time which are already significant for a $1.5 \mathrm{~km}$ tunnel. For reference, the models took 4 to 7 days to run on an enterprise level minimum 32 CPUs computational machine, with the larger fires taking longer.

The tunnel is modelled to be airtight with no pressure relief other than the portal. We now believe that this airtightness results in unrealisticly high pressure causing large fluctuations stressing the FDS pressure solver. After many months looking into these oscillations, discussion with McDermott $[2,6]$ suggested introducing artificial micro vents along the tunnel to simulate leakage to reduce the stress on the pressure solver.

As shown in Figure 3, the magnitude of the oscillation became negligible by using 4 micro vents of 1 cell size at atmospheric pressure where the $55 \mathrm{MW}$ fire is located. Although micro vents reduced the mass flow oscillation to negligible, the velocity 


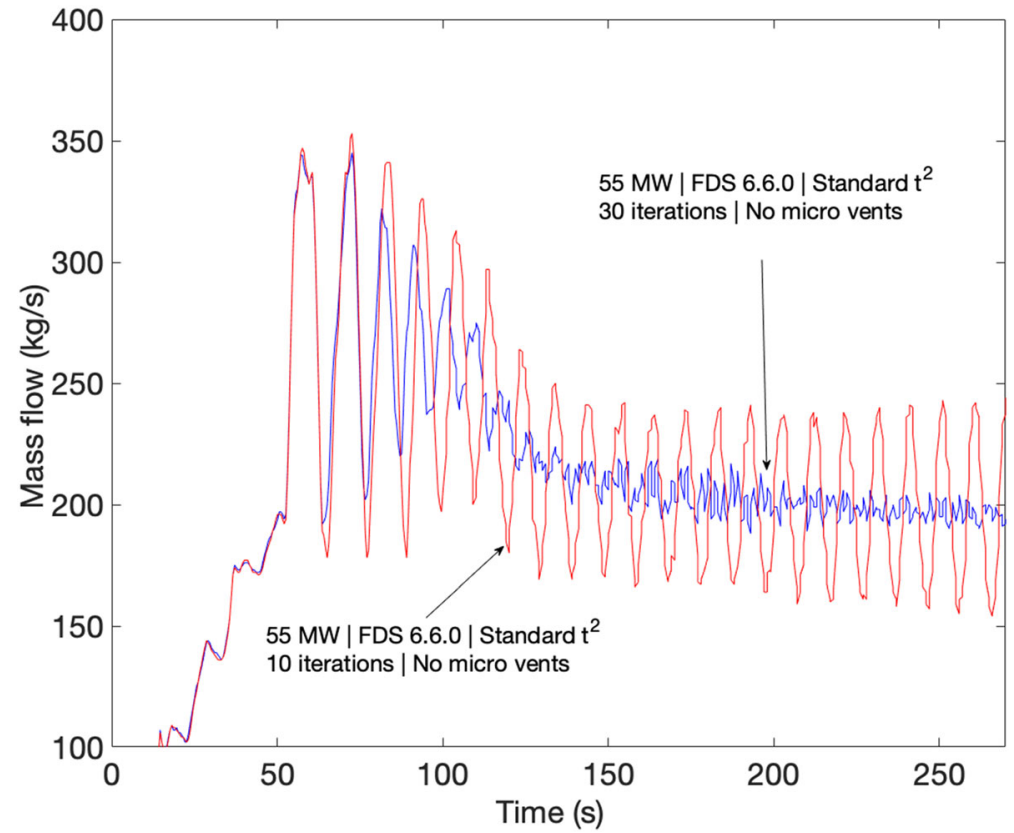

\section{Figure 2. Comparison of mass flow out between 10 and 30 pressure solver iferations. Mass flow oscillation became negligible at 30 iferations.}

error is still oscillating and increasing over time. The vents are unrealistic as they are not present in the real tunnel, and not all real fires would be near a vent.

When we were carrying out the investigation for the oscillation, we identified the lack of best practice guidelines in tunnel fire modelling. This includes questions of importance on various boundary conditions to simulate a tunnel network, obstruction, surface conditions, inclination, large fires, wind effects and others that could further complicate the model. It took us a long time to find the solution and no engineering projects have the time or resources to devote to numerical issues without guidances.

We can learn from other industries, for example the Architectural Institute of Japan [7] published a set of guidelines for the practical application of CFD to pedestrian wind environment around buildings or the US Nuclear Energy Agency [8] best practice CFD guidelines. Although there is some guidance in FDS User Guide [2], a broader guideline similar to those in the industries would be beneficial. The guideline would provide a good practice CFD modelling recommendations when using CFD to assess tunnel fire safety design.

The FDS community's plea for more tunnel fire validation cases is known by those who frequent the FDS forum. However this plea is unknown otherwise as tunnel fire modelling is a small community.

CFD modelling will become even more important in the design of major infrastructure. This letter is our call to the community and technical societies to collab- 


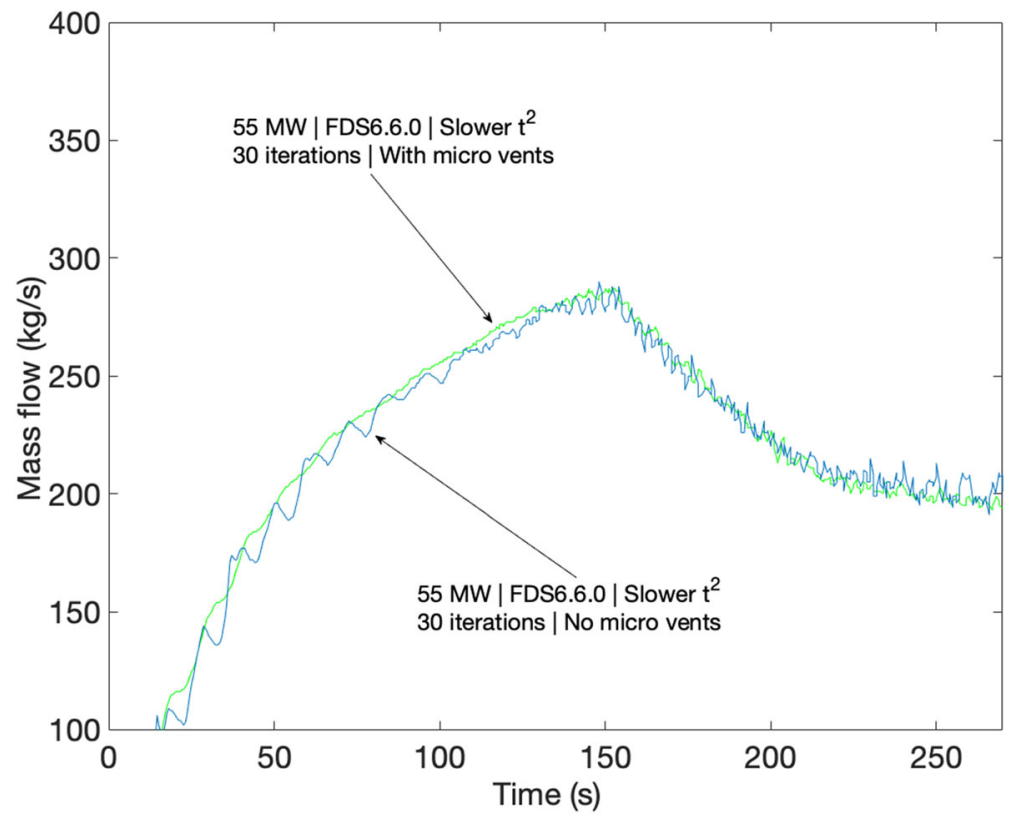

\section{Figure 3. Significant reduction in the magnifude of the oscillation if micro vents are introduced.}

orate in developing a best practice tunnel fire modelling guideline, developing more validation cases for tunnel fire models and lastly, a reminder not to ignore the wiggles.

\section{References}

1. International Transport Forum. Transport infrastructure investment and maintenance. ITF Transport Statistics (database). https://doi.org/10.1787/g2g55573-en. Accessed 16 Feb 2020

2. McGrattan K, Hostikka S, McDermott R, Floyd J, Weinschenk C, Overholt K (2018) Fire dynamics simulator user's guide, 6th edn. NIST and VTT Technical Research Centre of Finland, Espoo. 10.6028/NIST.SP.1019

3. Ang CDE, Rein G, Peiro J, Harrison R (2016) Simulating longitudinal ventilation flows in long tunnels: comparison of full CFD and multi-scale modelling approaches in FDS6. Tunn Undergr Space Technol 52:119-126. https://doi.org/10.1016/j.tust.2015.11.003

4. Vermesi IM, Rein G, Collella F, Valkvist M, Jomaas G (2017) Reducing the computational requirements for simulating tunnel fires by combining multiscale modelling and multiple processor calculation. Tunn Undergr Space Technol . https://doi.org/10.1016/ j.tust.2016.12.016

5. Gresho PM, Lee RL (1981) Don't suppress the wiggles - they're telling you something!. Comput Fluids 9(2):223-253. https://doi.org/10.1016/0045-7930(81)90026-8

6. McDermott R (2018) Personal Communication 
7. Tominaga Y, Mochida A, Yoshie R, Kataoka H, Nozu T, Yoshikawa M, Shirasawa T (2008) AIJ guidelines for practical applications of CFD to pedestrian wind environment around buildings. J Wind Eng Ind Aerodyn 96(10-11):1749-1761. https://doi.org/ 10.1016/j.jweia.2008.02.058

8. OECD Nuclear Energy Agency (2015) Best practice guidelines for the use of CFD in nuclear reactor safety application-revision. OECD

Publisher's Note Springer Nature remains neutral with regard to jurisdictional claims in published maps and institutional affiliations. 